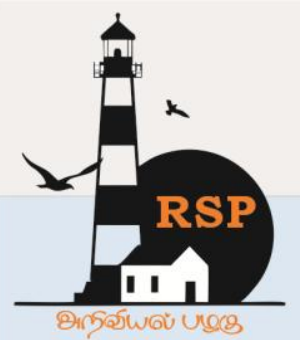

Special Issue of First International Conference on Advancements in Research and Development

\title{
Design and Fabrication of Less Cost and Efficient Delta 3D Printer Parts
}

\author{
A Vetrivel ${ }^{1}$, P $_{\text {imal }}{ }^{2}, J$ Vishwak Balaji ${ }^{3}$, H Yaser Arafat ${ }^{4}$ \\ ${ }^{1}$ Assistant Professor, Department of Mechanical Engineering, SNS College of Technology, Coimbatore- \\ 641035, Tamilnadu, India. \\ ${ }^{2,3,4}$ Student, Department of Mechanical Engineering, SNS College of Technology, Coimbatore-641035, \\ Tamilnadu, India. \\ vishwakjaishankar@gmail.com ${ }^{1}$
}

\begin{abstract}
This project is to fabricate the most essential parts of Delta type $3 D$ printer parts so as to make it more efficient in cost and working. This project has 3 vital parts of a 3D printer and they are Effector, Rod end bearings, Connecting rod (Diagonal rod). The Effector is a component that holds the hot end nozzle and other heat dissipating material within it and we in our project made a multi utility Effector so as to hold many hot ends such as Laser cutting, CNC tool, Food extrusion and 3D printing hot end. This Effector is also categorized into two as uphold and bottom hold since uphold and down hold. Rod end bearings are the motion transmission bearings that would transmit motion in a spherical path. We have made a different mechanism to transmit the motion same as to rod end bearing by coupling two universal joints and making some modification in it and made it cheaper in cost and efficient in working process. The connecting rod is the linking rod between the carriage and the effector. This connecting rod is used to transmit the motion from the carriage to the effector and this works in accordance to the design imbedded on the printer. The conventional 3D printer has carbon fibre pipes as their connecting rod and in this project this connecting rod is changed to steel and this one is made so as to withstand the load acting on it and cost efficient. All these parts are connected and made as a single setup and can be used in any delta type $3 D$ printer. The overall cost of this setup is $1 / 2$ times the cost of the conventional setup.
\end{abstract}

Keywords:3D Printer, Diagonal rod, Rod and Bearing, Delta type printer, 3D Printing.

\section{Introduction to 3D Printing}

The 3D printing process builds a threedimensional object from a computer-aided design (CAD) model, usually by successively adding material layer by layer, which is why it is also called additive manufacturing. The 3D printing has various process to create three dimensional object by combining the material in form of layer by layer. In 1990s, 3D-printing are only used for rapid prototyping. But later in 2019s precision, some 3D printers are very useful for production technology.
Main advantage of 3D printing is to produce very complex shapes, sizes and structural 3D printed parts in a digital 3D model or a CAD file.[1-4]

\section{Summary of Literature Review}

From the above literature's we can know that the efficient and less weight 3D printing parts can achieve by many different possible ways. The simple and efficient possible way that can be cost effective and productive in terms of quantity is by having simple mechanism is using coupled universal joint in place of rod end bearing. The 


\section{www.rspsciencehub.com}

alternative methods for weight reduction are using steel and alternative effector design and material for effective working.

\section{Construction for 3D Printer Parts}

This prototype is generally for components generally below 7" this can be manufactured for higher size with higher specification in larger scale for different operating specifications. The process the universal-joint is that, as the two shafts which it unites are rotated when at an angle to each other, it imparts to the driven shaft a non-uniform rotational velocity which becomes very erratic as the angle between the shafts approaches $90 \mathrm{deg}$. The efficient way to reduce the weight of the $3 \mathrm{D}$ printer is to change the material or to change the working mechanism of the part, the weight is reduced so as to gain the accuracy because the excess weight acts as a deviating force to change the geometry and accuracy of the desired prototype. Here, in our project we have changed the materials of Effector, Rod end bearings and Diagonal rod. We have altered the material of Effector from steel or carbon fiber to $\mathrm{ABS}$ and MS, the rod end bearing is replaced by coupled U-V joint and it is made up of ABS, Diagonal rod is replaced by Steel bike spokes because it has all its compression and tension withstanding ability. [3-5]

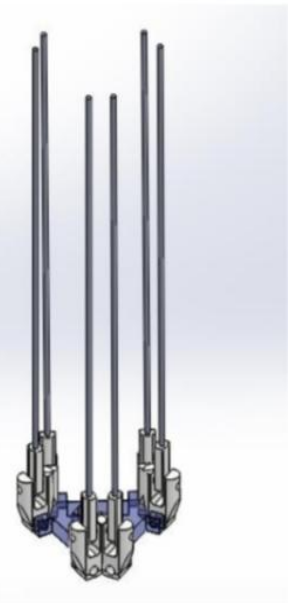

Fig.1. Design for the Prototype

\section{Working Principle}

A 3D printer essentially works by extruding molten plastic through a tiny nozzle that it moves around precisely under computer control. 3D
Volume 02 Issue 08 August 2020

printer prints the material in a layer by layer format. Delta 3D printers also use the Cartesian coordinate system, but do not use linear motion tracked movement to deposit the filament. Instead, they use three arms, each consisting of a parallelogram. They also move from one $\mathrm{X}$ or $\mathrm{Y}$ point to another, but do so by changing the angles of these parallelograms.

A heim Joint consists of a threaded rod with the circular head, it also has a ball bearing attached to the head. Heim joints are used in suspension. Heim joints are used to link both upper and lower control arms. Heim joints can be used on drag links, or tie rods.

\section{Design and Analysis of Fixture}

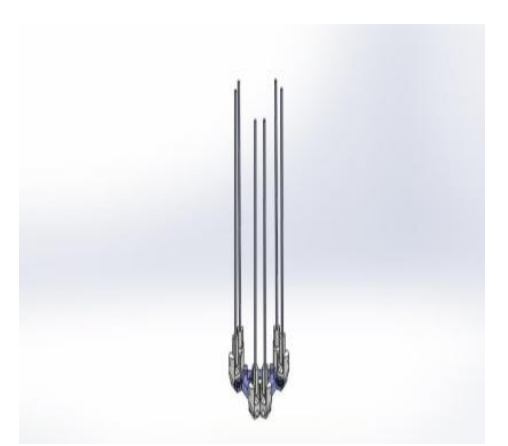

Fig.2. Isometric View

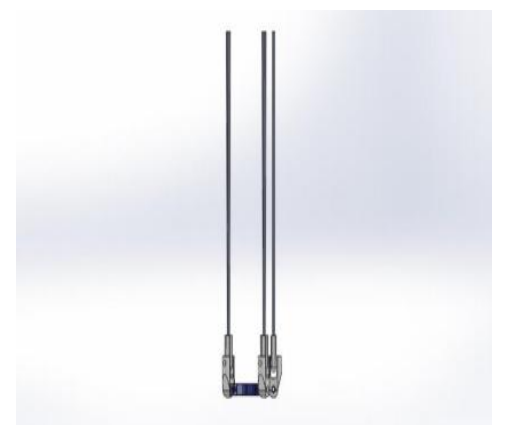

Fig.3. Front View

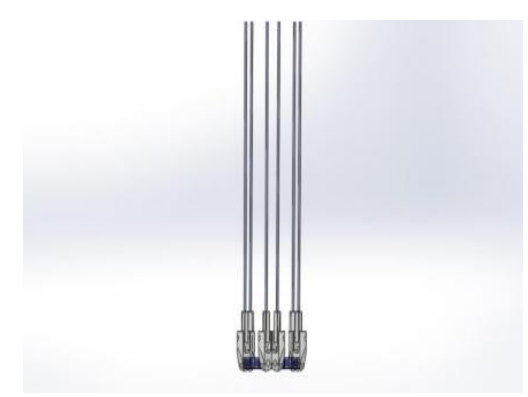


Fig.4. Side View

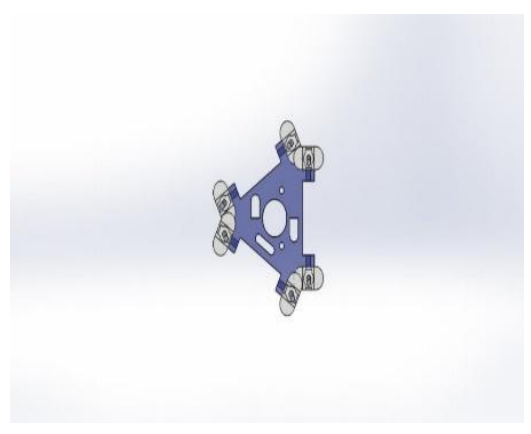

Fig.5. Top View

\section{Calculations}

Values entered in this calculation are higher than the practical value. It's done to get the desired value even at higher load conditions than the load at workplace. Diameter of steel shall be used = $2 \mathrm{~mm}$ (it's the least diameter that can be used, this value is used to check the metal characteristic at lower diameter than our desired diameter.)

1. Load acting $=4 \mathrm{~N}$ (two times than the practical load)

2. Cross section $=$ Round

3. Area $=3.14 * \mathrm{r} 2=0.00000314 \mathrm{~m} 2$

4. $\mathrm{E}($ steel $)=215 \mathrm{Gpa}$

5. Length of $\operatorname{rod}=220 \mathrm{~mm}$

6. Stress $=$ force $/$ Area $=4 / 0.00000314=$ $1.27 * 106 \mathrm{~N} / \mathrm{m} 2$

7. $\mathrm{E}=$ Stress $/$ Strain $=215 * 109=1.27 * 109 /$ Strain

8. Strain $=5.9 * 10-6$

9. Strain $=$ Change in length $/$ Original Length

Change in Length $=0.2 \mathrm{~mm}$ (it shows that theoretically spokes steel can withstand load even at smaller diameter with minimum deflection under load.)

Here, the Diagonal is placed at a minimum angle of $22^{\circ}$ so as to get the maximum stability of the Effector during the printing process. These angles are found using the Pythagoras theorem.

Table 1. Comparison Table

\begin{tabular}{|l|l|}
\hline Mini angle & Speed multiplier \\
\hline $22.5^{\circ}$ & 2.41 \\
\hline $20^{\circ}$ & 2.75 \\
\hline
\end{tabular}

\begin{tabular}{|l|l|}
\hline $17.5^{\circ}$ & 3.17 \\
\hline $15^{\circ}$ & 3.73 \\
\hline $12.5^{\circ}$ & 4.51 \\
\hline
\end{tabular}

7. Material Required

Table 2. Material Need to be Purchased

\begin{tabular}{|l|l|l|}
\hline Material & Dimension & Quantity \\
\hline $\begin{array}{l}\text { ABS } \\
\text { Effector }\end{array}$ & $\begin{array}{l}\text { As per the } \\
\text { Design }\end{array}$ & 1 \\
\hline $\begin{array}{l}\text { MS } \\
\text { Effector }\end{array}$ & $\begin{array}{l}\text { As per the } \\
\text { Design }\end{array}$ & 1 \\
\hline U-V Joint & $\begin{array}{l}\text { As per the } \\
\text { Design }\end{array}$ & 12 \\
\hline Steel rod & $\begin{array}{l}\text { L=220mm, } \\
\text { D=3mm }\end{array}$ & 6 \\
\hline
\end{tabular}

\section{Conclusions}

This project is made with pre planning and it is reliable during the operation. Thus, we have completed the project successfully and this project helped us to know that period steps in completing a project and also engaging in the working environment.

\section{References \\ Journal}

[1] A Review paper on 3D-Printing Aspects and Various Processes Used in the 3DPrinting [1], 2017.

[2] 3D Printing Process Using Fused Deposition Modelling (FDM) Vinod G. Surange1, Punit V. Gharat2 [2], 2016.

[3] Utility and challenges of 3 D Printing Aman Sharma1, Harish Garg2 [3], 2016.

[4] Design and Development of a Computer Numeric Controlled 3D Printer, Laser Cutter and 2D Plotter all in one machine [4], 1979.

[5] Hardware Improvement of FDM 3D Printer: Issue of Bed Leveling Failures [5], 2014. 